\title{
Standard Operating Procedures for Anesthesia Management in Cytoreductive Surgery and Hyperthermic Intraperitoneal Chemotherapy Improve Patient Outcomes: A Patient Cohort Analysis
}

Fichmann, Dominique ; Roth, Lilian ; Raptis, Dimitri A ; Kajdi, Marie-Elisabeth ; Gertsch, Philippe ; Vonlanthen, René ; de Rougemont, Olivier ; Moral, Julio ; Beck-Schimmer, Beatrice ; Lehmann, Kuno

DOI: https://doi.org/10.1245/s10434-019-07644-w

Posted at the Zurich Open Repository and Archive, University of Zurich ZORA URL: https://doi.org/10.5167/uzh-177651

Journal Article

Accepted Version

Originally published at:

Fichmann, Dominique; Roth, Lilian; Raptis, Dimitri A; Kajdi, Marie-Elisabeth; Gertsch, Philippe; Vonlanthen, René; de Rougemont, Olivier; Moral, Julio; Beck-Schimmer, Beatrice; Lehmann, Kuno (2019). Standard Operating Procedures for Anesthesia Management in Cytoreductive Surgery and Hyperthermic Intraperitoneal Chemotherapy Improve Patient Outcomes: A Patient Cohort Analysis. Annals of Surgical Oncology, 26(11):3652-3662.

DOI: https://doi.org/10.1245/s10434-019-07644-w 


\section{STANDARD OPERATING PROCEDURES FOR ANESTHESIA MANAGEMENT IN CYTOREDUCTIVE SURGERY AND HYPERTHERMIC INTRAPERITONEAL CHEMOTHERAPY IMPROVE PATIENT OUTCOMES. A PATIENT COHORT ANALYSIS.}

Dominique Fichmann¹, Lilian Roth ${ }^{1}$, Dimitri A. Raptis ${ }^{1}$, Marie-Elisabeth Kajdi², Philippe

Gertsch $^{1}$, René Vonlanthen ${ }^{1}$, Olivier de Rougemont ${ }^{1}$, Julio Moral², Beatrice Beck-Schimmer ${ }^{2}$, Kuno Lehmann ${ }^{1}$

${ }^{1}$ Department of Surgery, University Hospital Zurich, Switzerland

${ }^{2}$ Institute of Anesthesiology, University Hospital Zurich, Switzerland

Corresponding Author:

Prof. Dr. Kuno Lehmann, MD PhD

Department of Visceral Surgery and Transplantation

UniversityHospital Zurich

Raemistrasse 100

$\mathrm{CH}-8091$ Zurich, Switzerland

Phone: +41442553300

Fax: +414425544 49

Mail: kuno.lehmann@usz.ch

All authors declare no conflict of interest referring to this work. No third-party financial funds or materials were accepted or necessary for execution of this research project.

Running title: anesthesia management in cytoreductive surgery and hyperthermic intraperitoneal chemotherapy 
Keywords: Cytoreductive Surgery (CRS) and Hyperthermic Intraperitoneal Chemotherapy (HIPEC), Peritoneal Carcinomatosis

\section{Word Count:}

Abstract:

Main Text:

\section{Abbreviations}

CRS Cytoreductive surgery

HIPEC Hyperthermic intraperitoneal chemotherapy

$\mathrm{PCl} \quad$ Peritoneal Cancer Index

CC-Score Completeness of Cytoreduction Score

DPAM Diffuse peritoneal adenomucinosis

PMCA Peritoneal mucinous carcinomatosis

CRC Colorectal Carcinoma

SOP Standard operating procedure 


\section{SYNOPSIS}

We assessed the role of standard operating procedures (SOPs) for anesthesia management in a cohort of patients after CRS/HIPEC. Introduction of SOPs improved extubation rates, and decreased the rate of postoperative major complications and reoperations. 


\section{ABSTRACT}

Background: Cytoreductive surgery and hyperthermic intraperitoneal chemotherapy (CRS/HIPEC) offer survival benefits in well-selected patients with peritoneal tumors. The complexity of CRS/HIPEC requires surgical specialization. In contrast, limited data is available regarding the impact of anesthesia management. Here, we assessed the role of standard operating procedures (SOPs) for anesthesia on perioperative patient outcomes after CRS/HIPEC.

Patients and methods: Between 2009 and 2015, 112 CRS/HIPEC were performed at the University Hospital of Zurich. Procedures were grouped in an "early or late" group, before $(n=57)$, and after $(n=55)$ the introduction of SOPs, which defined management of fluids, serum albumin, hemostasis and body temperature.

Results: Introduction of SOPs significantly changed patient management. Patients received in total less colloids $(p=.03)$, and less diuretics $(p=.007)$. We noticed an increased substitution of albumin ( $p=.001$ ), and coagulation factors $(p=.008)$. Body temperatures were higher at the end of the operation $(p=.005)$, and more patients were extubated in the operating room ( $66 \%$ vs. $42 \%, p=.02)$. The rate of major complications $(p=.003)$ and reoperations $(p=.01)$ was reduced after introduction of SOPs. On multivariate analysis, two independent prognostic factors were identified: The use of $>2000 \mathrm{~mL}$ of colloids (OR 5.31, (1.06-26.56), $\mathrm{p}=.042$ ) was associated with major morbidity. In contrast, substitution of albumin (OR 0.12, (0.01-0.96, $\mathrm{p}=.046)$ was associated with better outcomes.

Conclusion: SOPs for perioperative anesthesia management have a major impact on outcomes of patients after CRS/HIPEC. Management of colloid administration was an independent prognostic factor for perioperative outcomes. This highlights the role of the anesthesiologist and the need for specialization beyond the surgical team. 


\section{INTRODUCTION}

Cytoreductive surgery (CRS) and hyperthermic intraperitoneal chemotherapy (HIPEC) has $\underline{\text { become a standard in the multimodal treatment options for peritoneal metastasis }} \underline{1,2}$. Together with modern systemic chemotherapy, CRS/HIPEC changed the perspective from palliation only to a chance to cure for many patients. For example, cure or long term survival is nowadays possible for patients with peritoneal metastasis from appendix tumors ${ }^{3}$, and at least a better tumor control can be achieved in many patients with colorectal peritoneal metastasis ${ }^{4}$, where a median survival above 40 months after CRS/HIPEC could be documented in many series ${ }^{4-8}$. Despite the lack of a randomized trial with modern systemic chemotherapy in the control group ${ }^{9-11}$, the Dutch randomized controlled trial $(\mathrm{RCT})^{12}$, and several cohort studies ${ }^{8,13-14}$ convince a growing number of medical and surgical oncologist to add CRS/HIPEC to the multimodal treatment of peritoneal metastasis.

The main argument against CRS/HIPEC is the potential morbidity and mortality of the procedure, in the specific setting of a highly-advanced disease ${ }^{15}$. Due to the long learning curve and complexity of the treatment ${ }^{16,17}$, there is a broad consensus regarding the need for centralization and high surgical expertise. In addition, CRS/HIPEC induces a complex pathophysiology before, during and after surgery. Recently, the group from Lyon published data highlighting that standardization of processes improves patient outcomes ${ }^{18}$. Their clinical pathway focused on patient selection, nutrition, renal protection, pain management, prevention, and early detection of complications. The group showed a reduction in the failure-to-rescue rate, and a better quality of care after introduction of their clinical pathway. However, despite the important role of the anesthesiologist during CRS/HIPEC, anesthesia management is clearly underreported in the current literature ${ }^{19-20}$, and may therefore be underestimated for the quality of CRS/HIPEC. The purpose of our study was therefore (i) to assess the effect of standard operating procedures (SOPs) for anesthesia 
management after its implementation, and (ii) to define clinically relevant factors that influence patient outcomes after CRS/HIPEC. 


\section{PatientS AND Methods}

\section{Patients}

Between January 2009 and December 2015, 112 complete CRS/HIPEC procedures were performed at the University Hospital of Zurich. Patients with explorative laparotomy or incomplete CRS, and therefore no HIPEC, were excluded. In 2012, the SOP was introduced for anesthesia management to create a uniform standard. Procedures were grouped in an early group before introduction of the SOP from 2009 to 2012, and a late group from 2012 to 2015. Patient data were extracted from anesthesia protocols and patient records. The study protocol was approved by the local institutional review board (cantonal ethics commission, Zurich, Switzerland; KEK 2015-0331), and reporting was based on the STROBE checklist for reporting clinical studies ${ }^{21}$.

\section{Patient selection}

Patients were selected for CRS/HIPEC based on the type of primary tumor, the absence of extraperitoneal disease, and a good performance status. Age was not a selection criterion. All patients were presented in an interdisciplinary tumor board, where systemic treatment was recommended before CRS/HIPEC in patients with aggressive carcinomas. Patients with non-invasive disease (pseudomyxoma) were directly operated. Informed consent was obtained from every patient.

\section{Surgical management}

Cytoreductive surgery was performed according to standardized protocols, and by a constant team. In the pilot phase the team was supported and supervised by an expert surgeon (P.G.) as recommended by others ${ }^{17}$. After midline incision, the abdomen was explored, the peritoneal cancer index (PCI) calculated and resectability assessed. Cytoreductive surgery included resection of the major and minor omentum, and resection of diseased organs or peritoneum in patients with secondary carcinomatosis. In mesothelioma patients, 
total peritonectomy was performed. HIPEC was performed with the open coliseum technique for 90 minutes at $42^{\circ} \mathrm{C}$ with mitomycin $(15-30 \mathrm{mg} / \mathrm{m} 2 x B S A)$, or cisplatin $(50-75 \mathrm{mg} / \mathrm{m} 2 x B S A)$, and doxorubicin (15mg/m2xBSA). Protective ileostomies were placed if more than one colonic or a low rectal anastomosis were performed.

\section{Anesthesia management}

\section{Before 2012, the choice of anesthesia management during CRS/HIPEC was an} individual decision of every single anesthesiologist. In 2012, a standard operating procedure (SOP) was introduced based on the data from Kajdi et al ${ }^{19}$. This SOP focused mainly on less invasive monitoring (no pulse contour cardiac output, $\mathrm{PiCCO}$, measurement), fluid or volume management with less colloids, avoidance of hypalbuminemia as a surrogate for the oncotic pressure, and management of hemostasis and hypothermia (Figure 1). The surgical procedure was separated into defined periods such as the preoperative phase, anesthesia induction, CRS, HIPEC, restitution and the postoperative phase. In the preoperative phase, patients were admitted electively to the hospital the day prior surgery for bowel preparation and hydration. Due to the expected enteral fluid loss and volume shift by osmotic bowel preparation with Macrogol 22 and for nephroprotection prior to HIPEC, $2000 \mathrm{~mL}$ of crystalloids were admitted intravenously overnight. During anesthesia induction, intraoperative monitoring was standardized to electrocardiogram (ECG), pulse oximetry, arterial and central venous line, a nasopharyngeal temperature probe, and a urinary catheter. A nasogastric tube was inserted to decompress the stomach. If no contradictions were evident, thoracic epidural anesthesia was installed before surgery and used up to the third postoperative day. Induction of general anesthesia was performed with propofol, maintenance by volatile anesthetics, such as sevoflurane or desflurane, or by a continuous infusion of propofol.

During CRS, fluid management was kept restrictive towards a physiologic diuresis. Crystalloids were substituted with a rate of $6-12 \mathrm{ml} / \mathrm{kg} / \mathrm{h}$ and colloids with a rate of 2-4 $\mathrm{ml} / \mathrm{kg} / \mathrm{h}$. In this context, albumin was not used for volume replacement. The goal was to 
achieve a target diuresis of $\geq 2 \mathrm{ml} / \mathrm{kg} / \mathrm{h}$. During CRS, the minimal urine output was set to $\mathbf{5 0}$

$\mathrm{ml} / \mathrm{h}$. During HIPEC, an uine output at $100 \mathrm{ml} / \mathrm{h}$ was targeted to avoid nephrotoxic effects of HIPEC. Coagulation was analyzed by ROTEM® (Rotational

Thromboelastometry) during prolonged CRS, and substituted by single factors. Hematocrit and ionized serum calcium was monitored by repeated blood gas analyses. Normothermia was achieved by aggressive warming and cooling of patients by warmed/cooled infusion, and external heating and cooling. The target temperature range of patients was $35-38^{\circ} \mathrm{C}$, normothermia was aimed at the end of the procedure $\left(36-37^{\circ} \mathrm{C}\right)$.

Usually during extensive CRS or towards the end of CRS, albumin was substituted with $20 \%$ human albumin to reach a target level of $>15 \mathrm{~g} / \mathrm{L}$ in serum (normal value: $35-52 \mathrm{~g} / \mathrm{L}$ ). Albumin was not substituted for volume replacement but to substitute a sufficient blood level to maintain the oncotic pressure. After albumin substitution, serum levels were checked in the following hours, and repeated only if not within the targeted range. During restitution, physiological conditions were re-established, and patients were prepared for extubation. Postoperatively, patients were transferred to the intensive care unit (ICU).

\section{Assessment of postoperative outcomes}

Postoperative complications were discussed during a weekly morbidity and mortality conference and graded by the Clavien/Dindo score ${ }^{23}$. Complications grade $\geq 3 \mathrm{~b}$, requiring an intervention under general anesthesia, reoperation or readmission to the ICU, were defined as "major" morbidity.

\section{Statistical analysis}

Continuous variables were compared with the Student $t$, Mann-Whitney U, one-way ANOVA, and Kruskal-Wallis tests, where appropriate. Differences among proportions derived from categorical data were compared using the Fischer's Exact or the Pearson $x 2$ tests, where appropriate. All $p$ values were two-sided and considered statistically significant if $p \leq 0.05$. All $p$ 
values in the univariate analysis were two-sided and considered statistically significant if $p \leq 0.05$. The backward stepwise logistic regression model was used to identify independent predictors of outcomes. Data are presented as mean (SD), median (IQR) and proportions (\%) with odds ratios $(95 \% \mathrm{Cl})$, where appropriate. Statistical analysis was performed using SPSS for Mac v23. 


\section{RESULTS}

\section{Patient characteristics}

During the study period from 2009 to $2015, \mathrm{n}=112$ consecutive and complete CRS/HIPEC procedures in $n=106$ patients were performed and included in the analysis. Patients after incomplete CRS and without HIPEC were excluded. Fifty-seven (51\%) procedures were performed before (early group), and fifty-five (49\%) after the introduction of standardized anesthesia SOPs (late group). There was no difference between the two groups for age, gender, body mass index (BMI), comorbidity, and medication (Table 1), indicating that there was no shift towards healthier or younger patients over the two periods. In addition, no difference was found for tumor types, except for a higher incidence of patients with disseminated peritoneal adenomucinosis (DPAM) $(p=0.050)$ in the late group.

\section{Surgical parameters}

Overall, the extent of peritoneal disease was higher, reflected by a higher $\mathrm{PCl}(p=.02)$ in the late group. Nevertheless, operating times remained constant, without differences between the two groups, and complete (CC-0) cytoreduction could be achieved in $>85 \%$ of the patients. Higher $\mathrm{PCl}$ values and a trend towards more complete CRS in the late group resulted in more complex resections. In detail, a higher rate of splenectomies $(p=.01)$, liver capsule resections $(p=.01)$, and colectomies $(p=.02)$ was performed. In addition, radical peritonectomy more often included peritoneal and mesenterial quadrants in the late group (Table 2). An ileostomy, usually placed if more than one colorectal anastomosis was performed, was more frequent in the late group $(p=.001)$. HIPEC was performed with a combination of mitomycin/doxorubicin for appendix and colorectal tumors, and cisplatin/doxorubicin for mesothelioma, gastric and ovarian tumors, and remained constant over time. In contrast, the dose of mitomycin increased from $15 \mathrm{mg} / \mathrm{m} 2 \times B S A$ to $30 \mathrm{mg} / \mathrm{m} 2 \times B S A$ over the two periods, and therefore, dosage of HIPEC was higher in the late 
group ( $p=.02$ ). Overall, the second period therefore includes patients with more complex CRS, and a higher dosage of HIPEC.

\section{Anesthesia management}

Introduction of SOPs for the anesthesia management significantly changed patient management. Standard intraoperative monitoring was limited to an arterial and central venous line as well as a urinary catheter, without the need for further invasive modalities such as extended hemodynamic monitoring with pulse contour cardiac output (PiCCO) unless indicated (Table 3). Thoracic epidural anesthesia was used in two third of patients if no contraindication was present. For anesthesia maintenance, volatile anesthetics were significantly more often used in the late group. Fluid management remained unchanged for a liberal use of crystalloids to maintain diuresis, but patients received less colloids $(p=.03)$, and less diuretics $(p=.007)$. Albumin levels were measured intraoperatively and kept $>15 \mathrm{mg} / \mathrm{l}$ to maintain the oncotic pressure, resulting in a higher use of albumin $(p<.001)$. Active surveillance of coagulation by thromboelastography resulted in a higher proportion of patients that received substitution of coagulation factors (e.g. fibrinogen, factor XIII, etc; $\mathrm{p}=.008)$. More details are given in Table 3 .

\section{Intraoperative cardiovascular parameters}

The mean arterial pressure (MAP) showed no difference between the groups (Figure 2). In contrast, a trend towards a lower central venous pressure (CVP) in the late group was observed, with a significant difference before the beginning of HIPEC (Figure 2). This may reflect the stricter volume management observed in the late group above. Patient core temperatures were actively corrected by heating and cooling and remained at higher physiologic levels at the end of the operation $(p=.005)$ (Figure 2). In addition, very low temperatures were avoided $(p=.02)$ in the late group. Although significant between the two groups, and observed at different time points, these temperature differences were small 
$\left(0.3^{\circ} \mathrm{C}\right)$. Finally, two third of patients were extubated directly in the operating room in the late group, compared to $42 \%$ in the early group $(p=.02)$ (Table 3$)$.

\section{Intra- and postoperative blood parameters}

There was no significant difference for hemoglobin, lactate levels were significantly higher in the late group just before HIPEC, and serum creatinine levels were comparable (Figure 3). The most striking difference was the higher serum albumin level in the late group, measured on arrival on the ICU, which remained significantly higher during the next twenty-four hours (Figure 3).

\section{Outcomes and multivariate analysis of prognostic factors}

Despite more complex surgery in in the late group, reflected by a higher $\mathrm{PCl}$ and more complex surgical procedures, the rate of major complications $(p=.003)$ and reoperations $(p=.01)$ was lower compared to the early group. The better outcomes also translated in a shorter hospital stay of patients in the late group (Table 4).

On multivariate analysis, two independent prognostic factors were identified. The use of $>2000 \mathrm{~mL}$ of colloids (OR 5.31, (1.06-26.56), $\mathrm{p}=.042$ ) was independently associated with major postoperative complications. In contrast, substitution of albumin for maintaining the oncotic pressure $(O R=0.12,(0.01-0.96) p=.046)$ was highly associated with an improved outcome. 


\section{DIscussion}

This study highlights the critical role of the anesthesiologist for patients undergoing

CRS/HIPEC. Two novel and independent prognostic parameters regarding major postoperative morbidity after CRSHIPEC were identified: First, the extensive use of colloids should be avoided, second, maintenance of the oncotic pressure by albumin substitution seems to be protective. Together, our findings highlight the role of the nonsurgical team during CRS/HIPEC, which is currently still underreported and underestimated. The majority of available studies are focused on the learning curve of the surgeon. Overall, they conclude that the experience of the surgical team depends on the case load, the individual experience of the surgeon ${ }^{16}$, and recommend performing around 100 procedures before reaching an expert level. One particular report from the Netherlands, highlights that the learning curve can be abbreviated if unexperienced teams are supervised by experienced surgeons ${ }^{17}$. This also confers to the situation of the present study, where the surgical team was trained by an experienced surgeon (P.G.), resulting into acceptable rates for perioperative morbidity, also among first patients. This should not undetermine the need or relevance of the surgical learning curve which was certainly still present. We believe that the major role of a senior surgeon is to avoid futile surgery, and to increase the rate of complete resections in borderline cases at the beginning of a center experience. Without any doubt, the surgical performance may have improved over time, reflected by constant operating times and a lower complication rate during the second period, despite more aggressive surgery. However, the surgeon's subjective impression that the patient went through the procedure more smoothly over time, triggered the present study, with a focus and assessment of anesthesiology parameters, particularly after the introduction of our institutional SOPs after our initial experience ${ }^{19}$. In the initial phase of the program, the minds were set, and CRS/HIPEC considered as an unpredictable high-risk procedure. Major physiologic changes and morbidity was expected by the anesthesiologists, and a major goal was to avoid complications of intraoperative 
chemotherapy, e.g. nephrotoxicity. As a result, volume management and maintenance of physiological diuresis was given highest priority, and substitution was probably excessive, particularly during cytoreduction, the initial phase of the procedure. This is well reflected by a higher central venous pressure and lower lactate levels before HIPEC. Very interestingly, aggressive and more invasive monitoring, e.g. the PiCCO system, during the initial phase did not avoid over-hydration, and monitoring and maintenance of diuresis at physiologic levels may be as good as sophisticated measurement of the volume status. This resulted in clinically relevant differences in outcomes, e.g. the reduced need for postoperative thoracic drains for pleural effusions, despite more extensive peritonectomy procedures, e.g. in the right upper quadrants. A study published in 2017 supports the presumption of a positive outcome through more restrictive volume management during CRS/HIPEC ${ }^{24}$. The authors conclude that a more restrictive fluid management with a maximum of 15.7 $\underline{\mathrm{mL} / \mathrm{kg} / \mathrm{h} \text { is associated with a lower overall comprehensive complication index. In the }}$ late group, we managed to reach a perioperative fluid rate of $10.2 \mathrm{~mL} / \mathrm{kg} / \mathrm{h}$, which fits well with the results of the mentioned study.

The impact of albumin substitution on postoperative outcomes was somehow a little surprise. Replacement of albumin is generally considered no longer indicated for volume replacement after large randomized trials, e.g. in patients with septic shock ${ }^{25}$. However, the setting of CRS/HIPEC may reflect a different situation due to the large fluid and protein loss after peritonectomy. Albumin substitution targeting serum levels above $15 \mathrm{mg} / \mathrm{L}$, maintains a physiologic oncotic pressure and may reduce massive third space leakage ${ }^{26}$. Regarding temperature management, the observed significant differences were very small, and therefore probably not clinically relevant. However together with a more physiologic volume management, it may contribute to the growing majority of patients that can be extubated in the operating room. Early extubation is critical for patient recovery, as already known from many other surgical fields ${ }^{27}$.

We would like to account the limitations of the present study, which represents the retrospective experience of a single center. However, the entire cohort of included patients 
was recorded in a prospective database, and anesthesia records could be completely recovered. An important question is which component of the SOP contributes to better outcomes. It remains unclear which are the critical factors. For example, preoperative hydration did not translate into a benefit in an RCT including patients undergoing general major surgery ${ }^{28}$. However, this may be different in preventing kidney injury prior to HIPEC, particularly if cisplatin is used, and is still performed in many centers. The need for preoperative hospitalization and costs will certainly trigger further prospective studies. Management of coagulation is another open dispute. The use of rotational thromboelastometry as performed in this study, has shown some improvements in early detection of coagulopathy ${ }^{29}$, and was also cost-effective, e.g. in the setting of liver transplantation ${ }^{30}$. However, this expensive technology may not be necessary for all patients undergoing CRS/HIPEC and could be reserved for patients with extensive CRS.

In conclusion, our data demonstrates a major impact of SOPs for perioperative anesthesia management on outcomes of patients after CRS/HIPEC. Independent factors associated with perioperative outcomes were albumin substitution, and the use of $>2000 \mathrm{~mL}$ of colloids. These findings highlight the need for a specialized and interdisciplinary management of patients with CRS/HIPEC, and warrants further studies. 


\section{REFERENCES}

1. Glehen O, Mohamed F, Gilly FN. Peritoneal carcinomatosis from digestive tract cancer: new management by cytoreductive surgery and intraperitoneal chemohyperthermia. Lancet Oncol. Apr 2004;5(4):219-228.

2. Sugarbaker PH. New standard of care for appendiceal epithelial neoplasms and pseudomyxoma peritonei syndrome? Lancet Oncol. Jan 2006;7(1):69-76.

3. Chua TC, Moran BJ, Sugarbaker PH, et al. Early- and long-term outcome data of patients with pseudomyxoma peritonei from appendiceal origin treated by a strategy of cytoreductive surgery and hyperthermic intraperitoneal chemotherapy. J Clin Oncol. Jul 10 2012;30(20):2449-2456.

4. Elias D, Gilly F, Boutitie F, et al. Peritoneal colorectal carcinomatosis treated with surgery and perioperative intraperitoneal chemotherapy: retrospective analysis of 523 patients from a multicentric French study. J Clin Oncol. Jan 1 2010;28(1):63-68.

5. Schneider MA, Eshmuminov D, Lehmann K. Major Postoperative Complications Are a Risk Factor for Impaired Survival after CRS/HIPEC. Ann Surg Oncol. Mar 062017.

6. Franko J, Shi Q, Goldman CD, et al. Treatment of Colorectal Peritoneal Carcinomatosis With Systemic Chemotherapy: A Pooled Analysis of North Central Cancer Treatment Group Phase III Trials N9741 and N9841. J Clin Oncol. Dec 122011.

7. Kuijpers AM, Mirck B, Aalbers AG, et al. Cytoreduction and HIPEC in the Netherlands: nationwide long-term outcome following the Dutch protocol. Ann Surg Oncol. Dec 2013;20(13):4224-4230.

8. Schneider MA, Eden J, Pache B, et al. Mutations of RAS/RAF Proto-oncogenes Impair Survival After Cytoreductive Surgery and HIPEC for Peritoneal Metastasis of Colorectal Origin. Ann Surg. Nov 2018;268(5):845-853.

9. Loupakis F, Cremolini C, Masi G, et al. Initial therapy with FOLFOXIRI and bevacizumab for metastatic colorectal cancer. N Engl J Med. Oct 23 2014;371(17):1609-1618.

10. Saltz LB, Clarke S, Diaz-Rubio E, et al. Bevacizumab in combination with oxaliplatin-based chemotherapy as first-line therapy in metastatic colorectal cancer: a randomized phase III study. J Clin Oncol. Apr 20 2008;26(12):2013-2019.

11. Van Cutsem $\mathrm{E}$, Kohne $\mathrm{CH}$, Hitre $\mathrm{E}$, et al. Cetuximab and chemotherapy as initial treatment for metastatic colorectal cancer. N Engl J Med. Apr 2 2009;360(14):1408-1417.

12. Verwaal VJ, Bruin S, Boot $H$, van Slooten $G$, van Tinteren H. 8-year follow-up of randomized trial: cytoreduction and hyperthermic intraperitoneal chemotherapy versus systemic chemotherapy in patients with peritoneal carcinomatosis of colorectal cancer. Ann Surg Oncol. Sep 2008;15(9):2426-2432.

13. Elias D, Lefevre JH, Chevalier J, et al. Complete cytoreductive surgery plus intraperitoneal chemohyperthermia with oxaliplatin for peritoneal carcinomatosis of colorectal origin. $J$ Clin Oncol. Feb 10 2009;27(5):681-685.

14. Amblard I, Mercier F, Bartlett DL, et al. Cytoreductive surgery and HIPEC improve survival compared to palliative chemotherapy for biliary carcinoma with peritoneal metastasis: A multi-institutional cohort from PSOGI and BIG RENAPE groups. Eur J Surg Oncol. 09 2018;44(9):1378-1383.

15. Chua TC, Yan TD, Saxena A, Morris DL. Should the treatment of peritoneal carcinomatosis by cytoreductive surgery and hyperthermic intraperitoneal chemotherapy still be regarded as a highly morbid procedure?: a systematic review of morbidity and mortality. Ann Surg. Jun 2009;249(6):900-907.

16. Kusamura S, Moran BJ, Sugarbaker PH, et al. Multicentre study of the learning curve and surgical performance of cytoreductive surgery with intraperitoneal chemotherapy for pseudomyxoma peritonei. Br J Surg. Dec 2014;101(13):1758-1765. 
17. Kuijpers AM, Hauptmann M, Aalbers AG, et al. Cytoreduction and hyperthermic intraperitoneal chemotherapy: The learning curve reassessed. Eur J Surg Oncol. Feb 2016;42(2):244-250.

18. Passot G, Vaudoyer D, Villeneuve L, et al. A Perioperative Clinical Pathway Can Dramatically Reduce Failure-to-rescue Rates After Cytoreductive Surgery for Peritoneal Carcinomatosis: A Retrospective Study of 666 Consecutive Cytoreductions. Ann Surg. Apr 2017;265(4):806-813.

19. Kajdi ME, Beck-Schimmer B, Held U, Kofmehl R, Lehmann K, Ganter MT. Anaesthesia in patients undergoing cytoreductive surgery with hyperthermic intraperitoneal chemotherapy: retrospective analysis of a single centre three-year experience. World journal of surgical oncology. 2014;12:136.

20. Schmidt C, Creutzenberg M, Piso P, Hobbhahn J, Bucher M. Peri-operative anaesthetic management of cytoreductive surgery with hyperthermic intraperitoneal chemotherapy. Anaesthesia. Apr 2008;63(4):389-395.

21. von Elm E, Altman DG, Egger $M$, et al. The Strengthening the Reporting of Observational Studies in Epidemiology (STROBE) statement: guidelines for reporting observational studies. Lancet. Oct 20 2007;370(9596):1453-1457.

22. Holte K, Nielsen KG, Madsen JL, Kehlet H. Physiologic effects of bowel preparation. Dis Colon Rectum. Aug 2004;47(8):1397-1402.

23. Lehmann K, Eshmuminov D, Slankamenac K, et al. Where Oncologic and Surgical Complication Scoring Systems Collide: Time for a New Consensus for CRS/HIPEC. World J Surg. Dec 15 2016(40):1075-1081.

24. Eng OS, Dumitra S, O'Leary M, et al. Association of Fluid Administration With Morbidity in Cytoreductive Surgery With Hyperthermic Intraperitoneal Chemotherapy. JAMA Surg. Dec 1 2017;152(12):1156-1160.

25. Caironi $P$, Tognoni $G$, Masson $S$, et al. Albumin replacement in patients with severe sepsis or septic shock. N Engl J Med. Apr 10 2014;370(15):1412-1421.

26. Arroyo V, Fernandez J. Pathophysiological basis of albumin use in cirrhosis. Ann Hepatol. May 2011;10 Suppl 1:S6-14.

27. Bulatao IG, Heckman MG, Rawal B, et al. Avoiding stay in the intensive care unit after liver transplantation: a score to assign location of care. American journal of transplantation : official journal of the American Society of Transplantation and the American Society of Transplant Surgeons. Sep 2014;14(9):2088-2096.

28. Serrano AB, Candela-Toha AM, Zamora J, et al. Preoperative hydration with $0.9 \%$ normal saline to prevent acute kidney injury after major elective open abdominal surgery: $A$ randomised controlled trial. European journal of anaesthesiology. Jun 2016;33(6):436-443.

29. Leemann $\mathrm{H}$, Lustenberger $\mathrm{T}$, Talving $\mathrm{P}$, et al. The role of rotation thromboelastometry in early prediction of massive transfusion. J Trauma. Dec 2010;69(6):1403-1408; discussion 14081409.

30. Smart L, Mumtaz K, Scharpf D, et al. Rotational Thromboelastometry or Conventional Coagulation Tests in Liver Transplantation: Comparing Blood Loss, Transfusions, and Cost. Ann Hepatol. November-December 2017;16(6):916-923. 


\section{Figure Legends}

\section{Figure 1: Zurich SOP for CRS/HIPEC}

The SOPs were introduced in 2012 to improve and standardize the perioperative management in patients undergoing CRS/HIPEC. ECG: Electrocardiogram. ROTEM® (Rotational Thromboelastometry).

Figure 2: Perioperative patient physiology.

Serum parameters before surgery (T0), before $(\mathrm{H} 0)$ and during $(\mathrm{H} 30, \mathrm{H} 60, \mathrm{H} 90) \mathrm{HIPEC}$, and at the end $(E)$ of the procedure. Minimal differences were observed for core temperature between early and late patients. No difference was observed for MAP, and a trend towards lower CVP in late patients.

\section{Figure 3: Serum parameters}

Analyses were performed before (PRE) surgery, before HIPEC $(\mathrm{H} 0)$, and on arrival on the intensive care unit (ICU), and on day 1 (D1) and day 2 (D2). 
TABLE 1: Patient characteristics

\begin{tabular}{|c|c|c|c|}
\hline Parameter & $\begin{array}{c}\text { Early Group } \\
(\mathrm{n}=57)\end{array}$ & $\begin{array}{l}\text { Late Group } \\
(n=55)\end{array}$ & $p$-value \\
\hline \multicolumn{4}{|l|}{ Gender } \\
\hline Male & $23(40.4 \%)$ & $26(47.3 \%)$ & \\
\hline Female & $34(59.6 \%)$ & $29(52.7 \%)$ & 0.57 \\
\hline Age & $52(43-58)$ & $50(42-59)$ & 0.55 \\
\hline BMI & $24.5(21.5-27.7)$ & $23.2(21.5-26.8)$ & 0.27 \\
\hline Charlson-Index & $6(6-8)$ & $6(6-9)$ & 0.87 \\
\hline \multicolumn{4}{|l|}{ ASA } \\
\hline $\mathrm{ASA} \leq \mathrm{II}$ & $54(94.7 \%)$ & $49(89.1 \%)$ & \\
\hline$A S A \geq I I I$ & $3(5.3 \%)$ & $6(10.9 \%)$ & 0.31 \\
\hline \multicolumn{4}{|l|}{ Comorbidity } \\
\hline Cardiovascular & $13(22.8 \%)$ & $22(40.0 \%)$ & 0.18 \\
\hline Pulmonary & $4(7.0 \%)$ & $6(10.9 \%)$ & 0.71 \\
\hline Renal & $2(3.5 \%)$ & $3(4.4 \%)$ & 0.73 \\
\hline Obesity (BMI > 35) & $8(14.0 \%)$ & $4(7.3 \%)$ & 0.25 \\
\hline \multicolumn{4}{|l|}{ Medication } \\
\hline None & $24(42.1 \%)$ & $25(45.5 \%)$ & 0.85 \\
\hline Betablocker & $2(3.5 \%)$ & $2(3.6 \%)$ & 1.0 \\
\hline Anti-hypertensive medication & $4(7.0 \%)$ & $1(1.8 \%)$ & 0.36 \\
\hline Combination of two or more & $5(8.8 \%)$ & $7(12.7 \%)$ & 0.55 \\
\hline Other & $22(38.6 \%)$ & $20(36.4 \%)$ & 0.85 \\
\hline \multicolumn{4}{|l|}{ Tumor type } \\
\hline Appendix & 33 (57.9\%) & $29(52.7 \%)$ & 0.70 \\
\hline DPAM & $13(22.8 \%)$ & $19(34.5 \%)$ & 0.05 \\
\hline PMCA & $8(14.0 \%)$ & $2(3.6 \%)$ & 0.09 \\
\hline Adenocarcinoma & 7 (12.3\%) & $4(7.3 \%)$ & 0.53 \\
\hline Signet ring cell & $4(7.0 \%)$ & $2(3.6 \%)$ & 0.68 \\
\hline Carcinoid & $1(1.8 \%)$ & $1(1.8 \%)$ & 1.0 \\
\hline Colorectal & $13(22.7 \%)$ & $18(32.7 \%)$ & 0.29 \\
\hline Synchronous & $5(38.5 \%)$ & $8(44.4 \%)$ & 0.39 \\
\hline Metachronus & $8(61.5 \%)$ & $10(55.6 \%)$ & 0.61 \\
\hline Mesothelioma & $5(8.8 \%)$ & $3(5.5 \%)$ & 0.72 \\
\hline Other & $6(10.6)$ & $5(9.1 \%)$ & 1.0 \\
\hline
\end{tabular}

ASA: American Society of Anesthesiologists, BMI: Body Mass Index, DPAM: diffuse peritoneal adenomucinosis, PMCA: peritoneal mucinous carcinomatosis. Interval data are shown as median with 1.-3. interquartile range. Categorical data are shown as absolute values $(n=)$ and percent of the respective total patient number. Mann-Whitney U-Test was used to test for differences between groups with interval data. Comparison in categorical data was performed using Pearson-Chi-Square test. ${ }^{*}$ Indicates statistically significant results. 
TABLE 2: Surgical characteristics

\begin{tabular}{|c|c|c|c|}
\hline Parameter & $\begin{array}{c}\text { Early Group } \\
(n=57)\end{array}$ & $\begin{array}{l}\text { Late Group } \\
(n=55)\end{array}$ & $p$-value \\
\hline \multicolumn{3}{|l|}{ CC-score } & 0.02 \\
\hline CC-0 & $44(77.2 \%)$ & $47(85.5 \%)$ & 0.34 \\
\hline CC-1 & $4(7.0 \%)$ & $1(1.8 \%)$ & 0.36 \\
\hline CC-2/3 & $9(15.8 \%)$ & $7(12.7 \%)$ & 0.78 \\
\hline OR time (min) & $510(450-720)$ & $625(480-735)$ & 0.26 \\
\hline Blood loss (mL) & $500(300-1500)$ & $350(200-800)$ & 0.05 \\
\hline \multicolumn{4}{|l|}{ peritonectomy procedures } \\
\hline none & $14(24.6 \%)$ & $8(14.5 \%)$ & 0.24 \\
\hline Selective & $18(31.6 \%)$ & $17(30.9 \%)$ & 1.0 \\
\hline Subtotal parietal & $21(36.8 \%)$ & $14(25.5 \%)$ & 0.22 \\
\hline Total parietal & $3(5.3 \%)$ & $3(5.5 \%)$ & 1.0 \\
\hline Parietal and mesenterial & $1(1.8 \%)$ & $13(23.6 \%)$ & $<0.01$ \\
\hline \multicolumn{4}{|l|}{ surgical procedures } \\
\hline Splenectomy & $4(7.0 \%)$ & $14(25.5 \%)$ & $<0.01$ \\
\hline Colon/rectum resection & $26(45.6 \%)$ & $37(67.3 \%)$ & 0.02 \\
\hline Small bowel resection & $15(26.3 \%)$ & $16(29.1 \%)$ & 0.74 \\
\hline Liver capsule resection & $19(33.3 \%)$ & $26(47.3 \%)$ & 0.01 \\
\hline Hysterectomy & $17(29.8 \%)$ & $21(38.2 \%)$ & 0.35 \\
\hline Gastric resection & $4(7.0 \%)$ & $2(3.6 \%)$ & 0.43 \\
\hline Loop ileostomy & $7(12.3 \%)$ & $32(58.2 \%)$ & $<0.01$ \\
\hline
\end{tabular}

PCl: peritoneal cancer index, CC-score: completeness of cytoreduction score (CC-0: No visible peritoneal carcinomatosis after CRS; CC-1: Nodules persisting < $2.5 \mathrm{~mm}$ after CRS; CC-2: Nodules persisting between $2.5 \mathrm{~mm}$ and $2.5 \mathrm{~cm}$; CC-3: Nodules persisting $>2.5 \mathrm{~cm}$ ) OR time: operating room time.

Interval data are shown as median with 1.-3. interquartile range. Categorical data are shown as absolute values ( $n=)$ and percent of the respective total patient number.

Mann-Whitney U-Test was used to test for differences between groups with interval data. Comparison in categorical data was performed using Pearson-Chi-Square test.

* Indicates statistically significant results. 
TABLE 4: Postoperative outcomes

\begin{tabular}{|c|c|c|c|}
\hline Parameter & $\begin{array}{l}\text { Early Group } \\
(n=57)\end{array}$ & $\begin{array}{l}\text { Late Group } \\
(\mathrm{n}=55)\end{array}$ & $p$-value \\
\hline \multicolumn{4}{|c|}{ Complication grading (Clavien) } \\
\hline none & $27(47.4 \%)$ & $36(65.4 \%)$ & 0.06 \\
\hline I & $1(1.8 \%)$ & $3(5.5 \%)$ & 0.36 \\
\hline II & $16(28.1 \%)$ & $14(25.4 \%)$ & 0.13 \\
\hline IIla & $4(7.0 \%)$ & $0(0 \%)$ & 0.12 \\
\hline IIllb & $5(8.8 \%)$ & $2(3.6 \%)$ & 0.44 \\
\hline IVa & $2(3.5 \%)$ & $0(0 \%)$ & 0.50 \\
\hline $\mathrm{IVb}$ & $0(0 \%)$ & $0(0 \%)$ & 1.0 \\
\hline V & $2(3.5 \%)$ & $0(0 \%)$ & 0.5 \\
\hline Major morbidity ( $\geq$ IIIb) & $11(19.3 \%)$ & $2(3.6 \%)$ & 0.01 \\
\hline Reoperation & $9(15.8 \%)$ & $2(3.6 \%)$ & 0.01 \\
\hline ICU stay (days) & $1(1-2)$ & $1(1-2)$ & 0.5 \\
\hline In-hospital stay (days) & $17(14-25)$ & $15(11-20)$ & 0.03 \\
\hline \multicolumn{4}{|c|}{ Gastrointestinal function } \\
\hline Flatulence (day) & $4(2-5)$ & $3(2-4)$ & 0.15 \\
\hline Passage of stool (day) & $6(5-7)$ & $4(3-5)$ & $<0.01$ \\
\hline \multicolumn{4}{|c|}{$\begin{array}{l}\text { HIPEC hyperthermic intraperitoneal chemotherapy, } P C \text { peritoneal carcinomatosis, } D P A M \text { diffuse peritoneal adenomucinosis, } P M C A \\
\text { peritoneal mucinous carcinomatosis, } A C \text { adenocarcinoma, } P C / \text { peritoneal cancer index, } I C U \text { intensive care unit }\end{array}$} \\
\hline \multicolumn{4}{|c|}{$\begin{array}{l}\text { Interval data are shown as median with 1.-3. interquartile range. Categorical data are shown as absolute values }(n=) \text { and percent of the } \\
\text { respective total patient number. Mann-Whitney U-Test was used to test for differences between groups with interval data. Comparison in } \\
\text { categorical data was performed using Pearson-Chi-Square test. }\end{array}$} \\
\hline
\end{tabular}




\section{ZURICH SOP for CRS/HIPEC}

\section{Preoperative \\ Bowel preparation \\ $2000 \mathrm{ml}$ i.v. crystalloids, over night}

\section{Anaesthesia Induction}

Cytoreduction (CRS)

Monitoring: ECG, arterial and central venous line, nasopharyngeal temperature probe, urinary catheter

Regional anesthesia: Epidural catheter if no contradictions Intubation: Rapid sequence induction, nasogastric tube Positioning: French position, heat pad below patient Antibiotics: Single shot of cefuroxim $1.5 \mathrm{~g}$ and metronidazole $500 \mathrm{mg}$ i.v.

Fluid substitution: Crystalloids 6-12 ml/ $/ \mathrm{kg}^{*} \mathrm{~h}$, colloids $2-4 \mathrm{ml} / \mathrm{kg}^{*} \mathrm{~h}$ Diuresis: Target diuresis $\geq 2 \mathrm{ml} / \mathrm{kg}^{*} \mathrm{~h}$; hands-on rule: $50 \mathrm{ml} / \mathrm{h}$ during $\mathrm{CRS}$ Body temperature: Core temperature $>35^{\circ} \mathrm{C}$

Oncotic pressure: Target albumin $>15 \mathrm{~g} / \mathrm{L}$, substitute before HIPEC Coagulation: Factor substitution according to ROTEM results Metabolism: arterial blood gas analysis

HIPEC

Fluid substitution: Crystalloids $6-12 \mathrm{ml} / \mathrm{kg}^{*} \mathrm{~h}$, colloids $2-4 \mathrm{ml} / \mathrm{kg}^{*} \mathrm{~h}$ Diuresis: Target diuresis $\geq 2 \mathrm{ml} / \mathrm{kg}^{*} \mathrm{~h}$; hands-on rule: $100 \mathrm{ml} / \mathrm{h}$ Body temperature: Start of cooling $30 \mathrm{~min}$ before HIPEC with cold infusions; target temperature: $35-38^{\circ} \mathrm{C}$

Oncotic pressure: Target albumin $>15 \mathrm{~g} / \mathrm{L}$

Coagulation: Factor substitution according to ROTEM results

Metabolism: arterial blood gas analysis; normo-natraemia (cave: oxaliplatin)

\section{Restitution}

Fluid substitution: Reduced application of fluids (crystalloids, colloids) Diuresis: Target diuresis $\geq 1 \mathrm{ml} / \mathrm{kg}^{*} \mathrm{~h}$

Body temperature: Active warming immediately after HIPEC, target temperature of $36-37^{\circ} \mathrm{C}$

Oncotic pressure: Target albumin $\geq 15 \mathrm{~g} / \mathrm{L}$

Extubation: in the OR

Postoperative

Free oral fluids

No antibiotics 


\section{ZURICH SOP for CRS/HIPEC}

Preoperative

\section{Anaesthesia Induction}

\section{Cytoreduction (CRS)}

HIPEC

\section{Restitution}

Postoperative

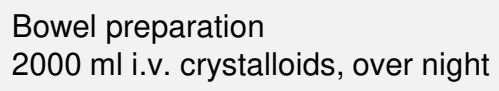

Monitoring: ECG, arterial and central venous line, nasopharyngeal temperature probe, urinary catheter

Regional anesthesia: Epidural catheter if no contradictions Intubation: Rapid sequence induction, nasogastric tube Positioning: French position, heat pad below patient Antibiotics: Single shot of cefuroxim $1.5 \mathrm{~g}$ and metronidazole $500 \mathrm{mg}$ i.v.

Fluid substitution: Crystalloids 6-12 ml/ $/ \mathrm{gg}^{*} \mathrm{~h}$, colloids $2-4 \mathrm{ml} / \mathrm{kg}^{*} \mathrm{~h}$ Diuresis: Target diuresis $\geq 2 \mathrm{ml} / \mathrm{kg}^{*} \mathrm{~h}$; hands-on rule: $50 \mathrm{ml} / \mathrm{h}$ during CRS Body temperature: Core temperature $>35^{\circ} \mathrm{C}$

Oncotic pressure: Target albumin $>15 \mathrm{~g} / \mathrm{L}$, substitute before HIPEC Coagulation: Factor substitution according to ROTEM results Metabolism: arterial blood gas analysis

Fluid substitution: Crystalloids $6-12 \mathrm{ml} / \mathrm{kg}^{\star} \mathrm{h}$, colloids $2-4 \mathrm{ml} / \mathrm{kg}^{\star} \mathrm{h}$ Diuresis: Target diuresis $\geq 2 \mathrm{ml} / \mathrm{kg}^{*} \mathrm{~h}$; hands-on rule: $100 \mathrm{ml} / \mathrm{h}$ Body temperature: Start of cooling $30 \mathrm{~min}$ before HIPEC with cold infusions; target temperature: $35-38^{\circ} \mathrm{C}$

Oncotic pressure: Target albumin $>15 \mathrm{~g} / \mathrm{L}$

Coagulation: Factor substitution according to ROTEM results Metabolism: arterial blood gas analysis; normo-natraemia (cave: oxaliplatin)

Fluid substitution: Reduced application of fluids (crystalloids, colloids) Diuresis: Target diuresis $\geq 1 \mathrm{ml} / \mathrm{kg}^{*} \mathrm{~h}$

Body temperature: Active warming immediately after HIPEC, target temperature of $36-37^{\circ} \mathrm{C}$

Oncotic pressure: Target albumin $\geq 15 \mathrm{~g} / \mathrm{L}$

Extubation: in the OR 


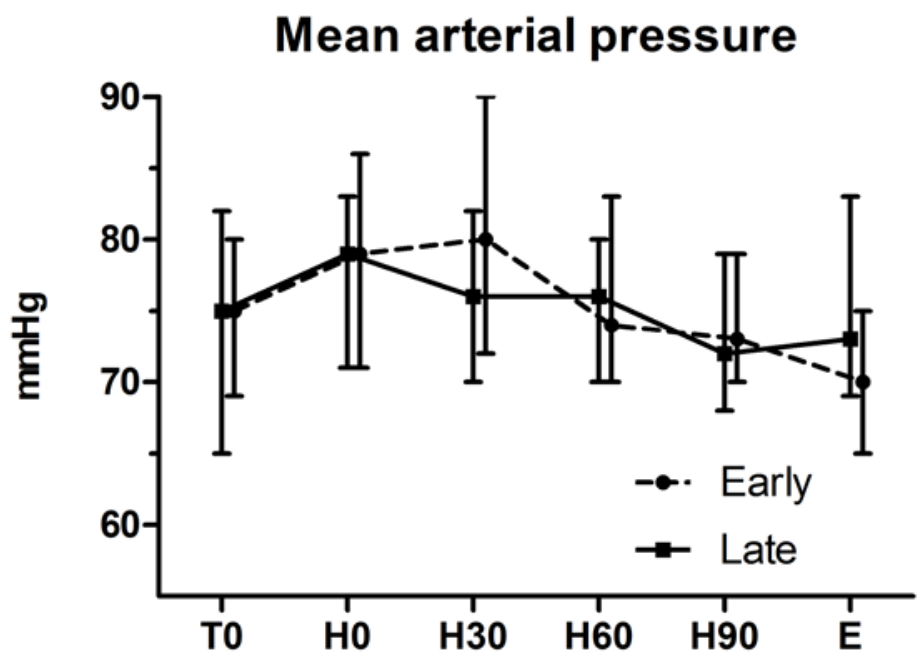

Central venous pressure

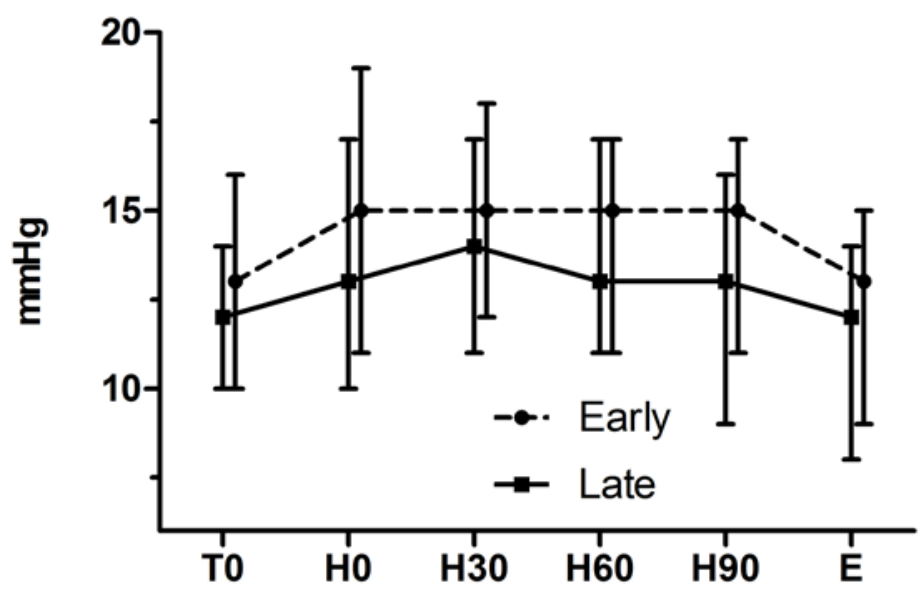

Core body temperature

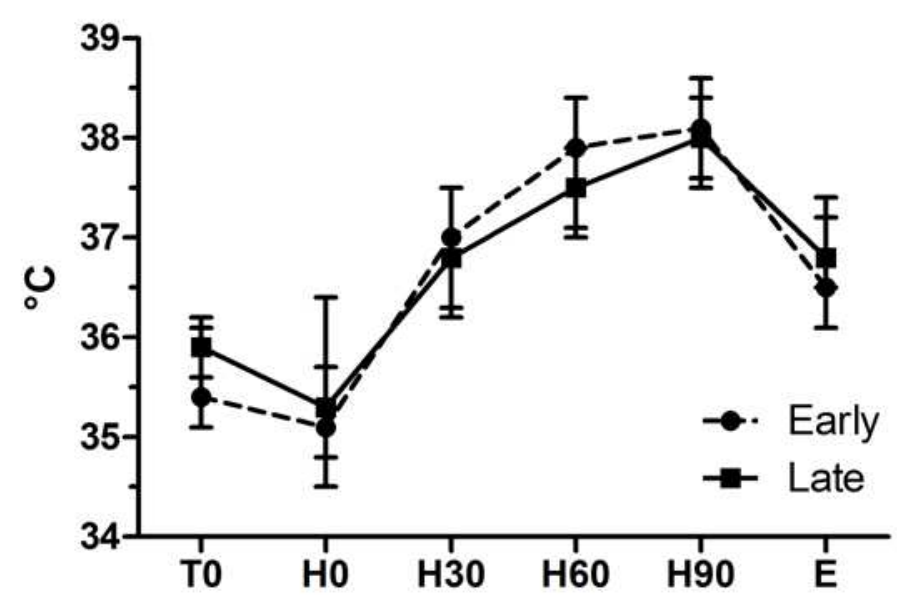


Hemoglobin

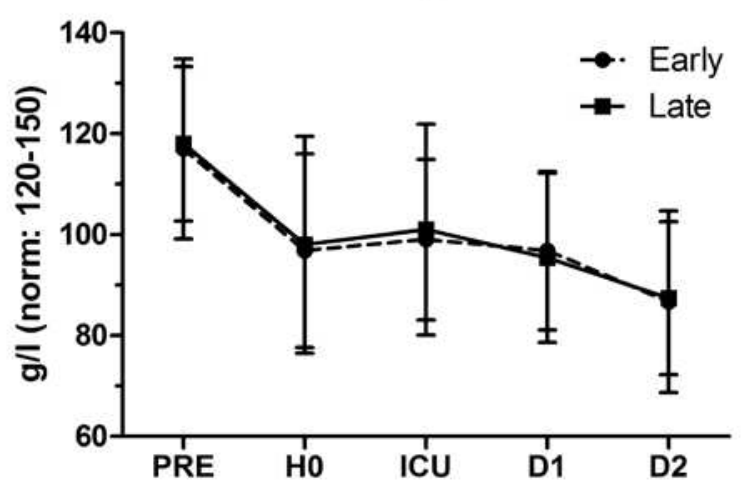

\section{Lactate}

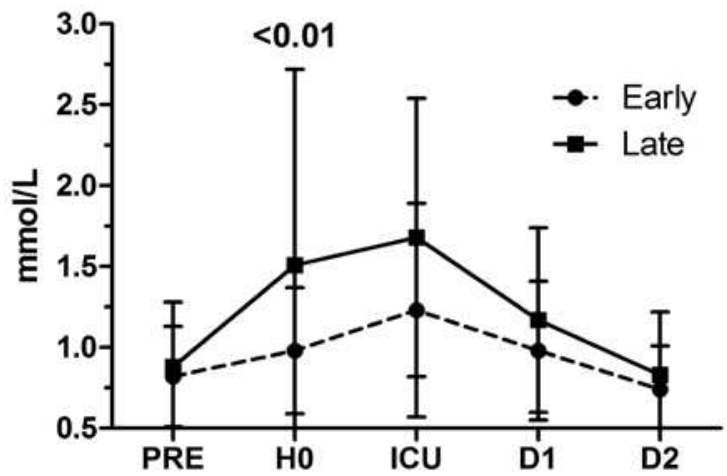

Creatinine

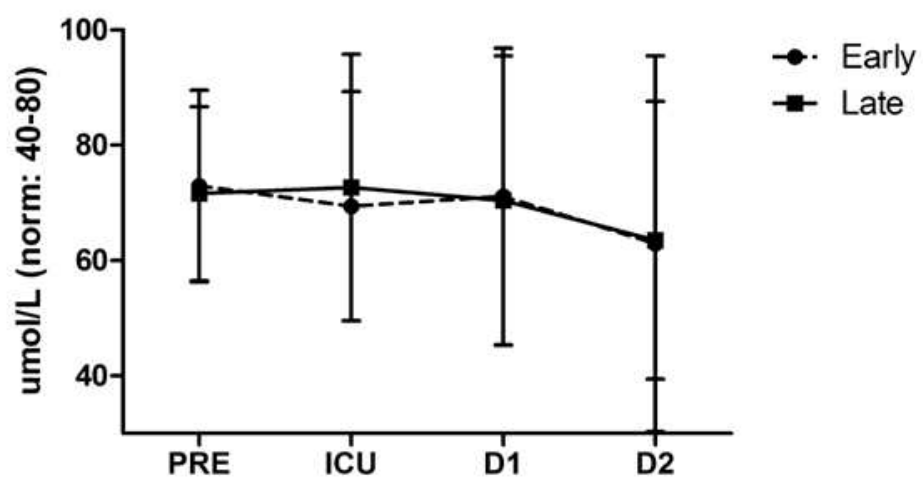

Albumin

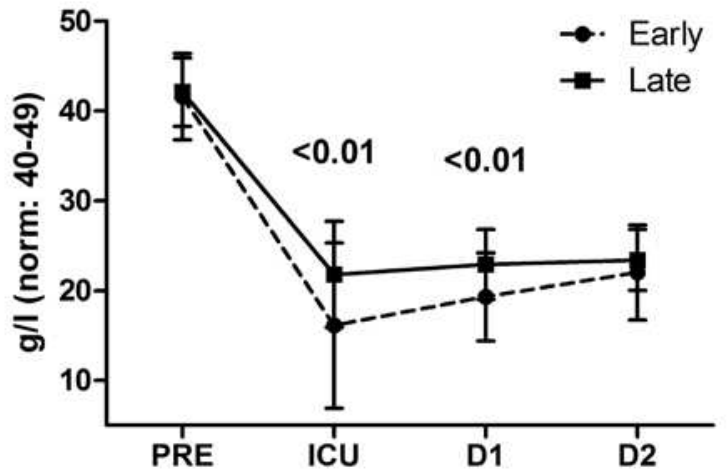

